\title{
Forma Arquitetônica e Função Estrutural da Igreja Nossa Senhora de Fátima em Brasília
}

\author{
ARAKAKI, Suyene Riether ${ }^{1}$ \\ AZAMBUJA, Eduardo Bicudo de Castro ${ }^{2}$ \\ SÁNCHEZ, José Manoel Morales ${ }^{3}$ \\ ${ }^{1}$ Universidade de Brasília, Brasil. suyenearakaki@gmail.com \\ ${ }^{2}$ Universidade de Brasília, Brasil. edazambuja@globo.com \\ 33niversidade de Brasília, Brasil. sanchez@unb.br
}

\begin{abstract}
Resumo
A Igreja Nossa Senhora de Fátima, primeiro templo católico construído no Plano Piloto, constitui um modelo de integração entre a forma arquitetônica e a função estrutural. Esta síntese característica dos projetos idealizados por Oscar Niemeyer e Joaquim Cardozo para os edifícios públicos de Brasília definiu-se como princípio conceptivo e é resultante do acúmulo de experiências em projetos anteriores que demonstram a persistência da forma como um dos aspectos de metodologia de projeto.

Os documentos técnicos produzidos para contemplar o projeto da igreja permitiram a construção de um modelo matemático simplificado, a partir do qual se realizou análise qualitativa da obra. $O$ estudo desvenda o arranjo estrutural proposto que possibilita o cumprimento das demandas da linguagem arquitetônica, mantendo a intenção de leveza que identifica os prédios deste período. $\mathrm{O}$ objetivo desta pesquisa é apresentar tal análise como ferramenta de concepção de projeto, de modo a facilitar o entrosamento entre as disciplinas da arquitetura e estruturas.
\end{abstract}

Palavras-Chave: Brasília; Niemeyer; Cardozo; análise estrutural qualitativa.

\begin{abstract}
The Igreja Nossa Senhora de Fátima, the first Catholic church built at Plano Piloto, is a model of integration between architectural form and structural function. The synthesis that features the projects conceived by Oscar Niemeyer and Joaquim Cardozo for public buildings of Brasilia was defined as a conceptive principle and results from the experiences attained in previous projects, wich demonstrate the persistence as an aspect of designing method.

The technical documents produced to contemplate the design of the church allowed the construction of a simplified mathematical model, from which qualitative analysis of the building was carried out. The study reveals that the proposed structural arrangement enabled the accomplishment with the demands of architectural language, while maintaining the intention of lightness that identifies the buildings of this period. The aim of this research is to present such analysis as a tool for designing projects, simplifying the association between the disciplines of architecture and structural engineering.
\end{abstract}

Key-Words: Brasília; Niemeyer; Cardozo; structural qualitative analysis. 


\section{Introdução}

Segundo Santa Cecília (2009), o caráter original da arquitetura moderna brasileira do século XX deveu-se à capacidade dos arquitetos adaptarem os ideais formulados na Europa à realidade do país. A intenção de incorporar a estrutura ao espaço arquitetônico, criando uma nova expressão plástica, e de alinhar os detalhes de projeto com a tecnologia existente nos canteiros de obra, determinou o uso preponderante do concreto armado como material estrutural.

Os desenhos de Oscar Niemeyer para os primeiros edifícios de Brasília demonstram o seu interesse em criar essa relação harmônica. Aproximando o diálogo entre 0 arquiteto e o engenheiro, Niemeyer conseguiu integrar à composição arquitetônica, o entendimento do comportamento estrutural e a prática das técnicas construtivas, formando um conjunto unificado e coerente (Figura 1).

Figura 1: Croqui de Oscar Niemeyer para a Catedral Metropolitana de Brasília.

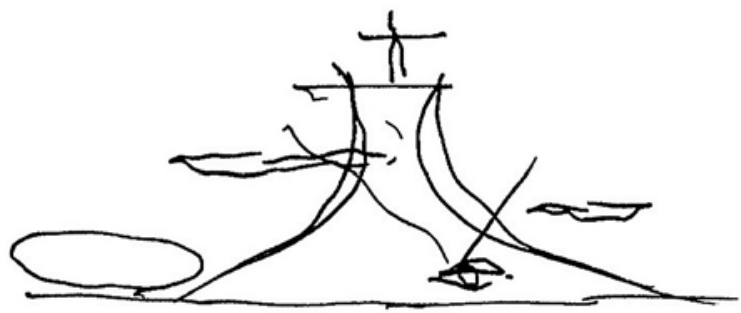

Fonte: http://www.niemeyer.org.br

O projeto da Catedral de Brasília seguiu essa síntese. Conforme descrito por Niemeyer (2002), a filosofia arquitetural integra a beleza com a puríssima solução estrutural que a viabiliza. O espaço arquitetônico surge pela repetição radial de dezesseis colunas de concreto armado unidas na base por um anel tracionado e acima por um anel comprimido. Os pilares possuem seção transversal variável, sugerindo o dimensionamento da quantidade de material a partir da necessidade decorrente dos esforços que atuam no elemento (Figura 2).

Figura 2: Modelo estrutural da Catedral Metropolitana de Brasília.

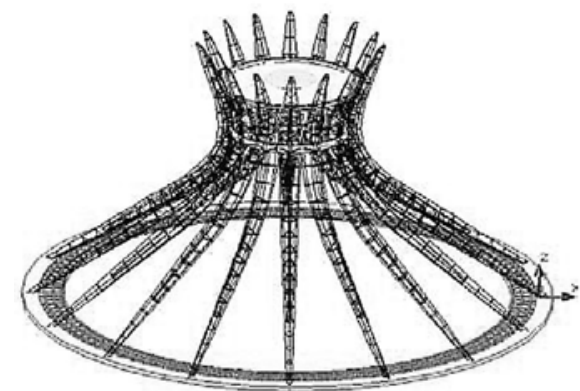

Fonte: TEATINI CLÍMACO, 2002

A forma e a disposição dos elementos estruturais da Catedral de Brasília permitem a leitura clara e direta dos caminhos percorridos pelas forças atuantes, algo que o engenheiro italiano Pier Luigi Nervi (1959) classificava como a intuição estática do prédio.

A idealização das formas arquitetônicas pela percepção do comportamento estático da estrutura eram princípios fundamentais do modo de projetar e construir de Nervi. Conforme Siegel (1966), Nervi acreditava que os desenhos devem ser consequência do conhecimento acerca da distribuição das forças e da busca pelas formas mais adequadas para tal encaminhamento, de modo simples e econômico, revelando sua sensibilidade estética expressa nos desenhos das formas estruturais e não apenas no cálculo das mesmas.

A análise de projetos construídos mostra que há dois tipos de arranjos estruturais, o primeiro, de fácil assimilação, aponta uma estrutura que se comporta como é apresentada, e o outro modelo, em que o caminho das forças, em uma observação inicial, torna-se mais difícil de ser percebido. Nervi empregou sistematicamente o primeiro tipo de arranjo em suas obras, expondo a estrutura, a função e o encaminhamento das forças atuantes nos projetos em concreto armado. A clareza da solução técnica apresentada no desenho da forma arquitetônica foi definida por Rosenthal (1962) como honestidade estrutural da edificação.

Para Siegel (1966), a forma correta de uma edificação é aquela que se torna mais adequada para a distribuição das forças e o desenho dos elementos estruturais deve estar de acordo com a distribuição dos esforços atuantes. Assim, pode-se definir como pureza estrutural, a intenção de se projetar manifestando com transparência o comportamento dos elementos que compõe a estrutura do prédio.

A verificação de uma determinada estrutura é feita através de uma análise quantitativa que envolve o lançamento das ações atuantes na edificação e a obtenção das suas respostas, os esforços e os deslocamentos nas diversas seções dos elementos estruturais. O processo é iterativo, ou seja, a cada vez que se repete gera resultados parciais usados na etapa seguinte até sua conversão para a solução desejada, e o dimensionamento irá convergir quando se alcançar a melhor solução de projeto.

Porém, uma análise qualitativa permite, com o uso de modelos matemáticos simplificados, avaliar de uma maneira mais rápida o comportamento de um determinado arranjo estrutural, através da visualização dos seus esforços e deslocamentos. A análise qualitativa possibilita o entendimento de 
sistemas estruturais utilizados em construções existentes e o refinamento do pré-dimensionamento a ser adotado em projetos futuros.

\subsection{Objetivo}

Esse trabalho tem por objetivo descrever, através de uma análise qualitativa, o comportamento estrutural da primeira ICSQ - Igreja Católica de Superquadra construída em Brasília, a Igreja Nossa Senhora de Fátima, localizada entre as quadras SQS 307 e SQS 308, inaugurada em 28 de junho de 1958, e a sua relação com a forma arquitetônica proposta no projeto de Oscar Niemeyer.

Quanto à história da construção da ICSQ, pretende-se evidenciar os aspectos mais importantes, início e término das obras, projetos arquitetônico e estrutural desenvolvidos e detalhes gerais da estrutura. Apresenta-se a concepção estrutural e a função das peças principais, lajes, vigas e pilares. O trabalho inclui a análise do modelo estrutural adotado, utilizando o software Ftool - Versão Educacional 3.0 para obtenção dos esforços e deslocamentos dos elementos.

\section{Descrição da Obra}

O Relatório do Plano Piloto de Brasília definiu na escala residencial a criação de uma sequência contínua de grandes quadras dispostas em ordem dupla ou singela, seguindo a configuração de vias e acessos, e a localização de diversos equipamentos e serviços, tais como, a igreja, a escola secundária, o cinema e o varejo do bairro. Define-se, então, a Igreja Católica de Superquadra - ICSQ como um equipamento constituinte do conjunto residencial.

A Igreja Católica da Superquadra 307/308, primeiro templo católico de Brasília, foi consagrada a Nossa Senhora de Fátima, em 1957, em cumprimento a uma promessa feita por D. Sarah Kubitschek, esposa do presidente Juscelino Kubitschek, após constatar uma grave doença na filha do casal, Márcia Kubitschek. Deste fato surge a Igreja Nossa Senhora de Fátima, apelidada de Igrejinha por suas pequenas dimensões (Tamanini, 2003).

A obra da Igrejinha, realizada pela Construtora Ibira Ltda. em 100 dias, foi supervisionada pela Associação das Pioneiras Sociais. A arquitetura foi desenvolvida por Oscar Niemeyer, sob a coordenação do arquiteto Nauro Esteves. O projeto de estrutura de concreto armado foi elaborado pelo engenheiro Joaquim Cardozo, coordenado por Victor Fadhul, engenheiro do quadro de servidores da NOVACAP - Companhia Urbanizadora da Nova Capital.
Algumas características do projeto da Igrejinha, como o desenho dos seus pilares, a utilização de paredes como elementos estruturais, a forma da sua cobertura e a distribuição das funções em planta, podem ser analisadas a partir de um projeto anterior desenvolvido por Niemeyer, a Casa Edmundo Cavanelas, construída na cidade de Pedro do Rio/RJ, em 1954 (Figura 3).

Figura 3: Casa Edmundo Cavanelas, croquis de Niemeyer.

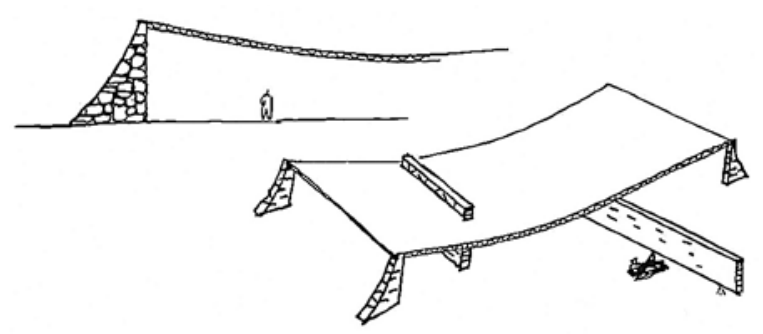

Fonte: Weintraub, 2011

Em ambos havia a intenção de propor leveza ao conjunto a partir do desenho da cobertura em um plano curvo com pontos de apoios reduzidos, sugerindo uma catenária. Na Casa Cavanelas, a cobertura é composta por telhas leves de fibrocimento, suportada em uma grelha formada por treliças metálicas que se apoiam nos quatro pilares e nas paredes de pedra (Figura 4).

Figura 4: Casa Cavanelas, distribuição das funções em planta.

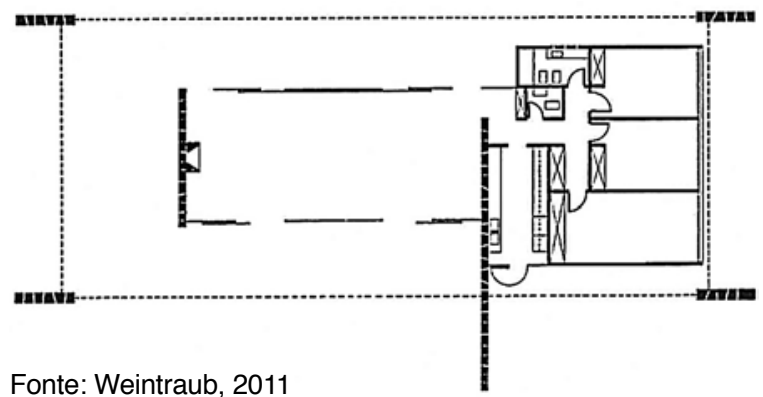

A percepção de leveza desejada por Niemeyer para o projeto da Igrejinha foi respeitada no sistema estrutural desenvolvido por Cardozo. A cobertura com área total de $362,5 \mathrm{~m}^{2}$ foi dividida em seis lajes apoiadas em cinco vigas invertidas, com espessuras que variam de $10 \mathrm{~cm}$ no trecho curvo central e de 25 a $30 \mathrm{~cm}$ nas extremidades em balanço.

As duas vigas do contorno da cobertura, posicionadas nas fachadas laterais do prédio, definem a forma arquitetônica e expressam a intenção de leveza do projeto de Niemeyer. Possuem seção transversal variável, apresentando $90 \mathrm{~cm}$ de altura no trecho central, diminuindo suavemente para 25 $\mathrm{cm}$, à medida que se aproximam dos três pilares de apoio. 
Os pilares denominados $\mathrm{P} 1, \mathrm{P} 2$ e $\mathrm{P} 3$, também fazem parte da concepção plástica do projeto arquitetônico e possuem seção transversal trapezoidal variável, determinada por uma curva na direção de sua altura. O pilar $\mathrm{P} 1$, localizado na entrada do prédio, inicia-se com uma altura de $450 \mathrm{~cm}$, os outros dois, P2 e P3, posicionados nos fundos da edificação, começam com $350 \mathrm{~cm}$. Os três elementos terminam, no encontro com as vigas da cobertura, com uma altura de $20 \mathrm{~cm}$ (Figura $5 \mathrm{e}$ Figura 6)

Figura 5: Planta baixa do projeto construído.

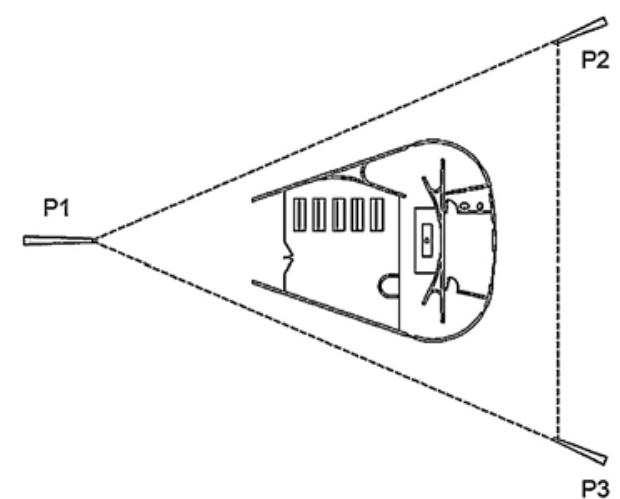

Fonte: Arakaki, 2012

Figura 6: Corte longitudinal do projeto construído.

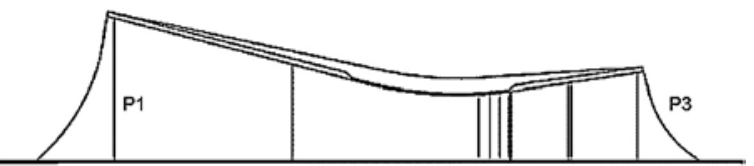

Fonte: Arakaki, 2012

Tanto as paredes externas que determinam a forma do prédio como a parede que separa o altar da sacristia foram projetadas como elementos estruturais de concreto armado. As alvenarias restantes, com função de vedação e isolamento, foram executadas com blocos cerâmicos (Figura 7).

O projeto apresenta fundações diretas com a utilização de sapatas de base retangular, isoladas no caso dos pilares da estrutura e corrida sob as paredes de concreto armado (Figura 8).

Vigas baldrames também apoiadas em sapatas isoladas foram lançadas para apoiar as paredes de vedação do interior do prédio e também como estrutura de travamento das fundações dos pilares P1, P2 e P3 (Figura 9).
Figura 7: Projeto da forma da cobertura.

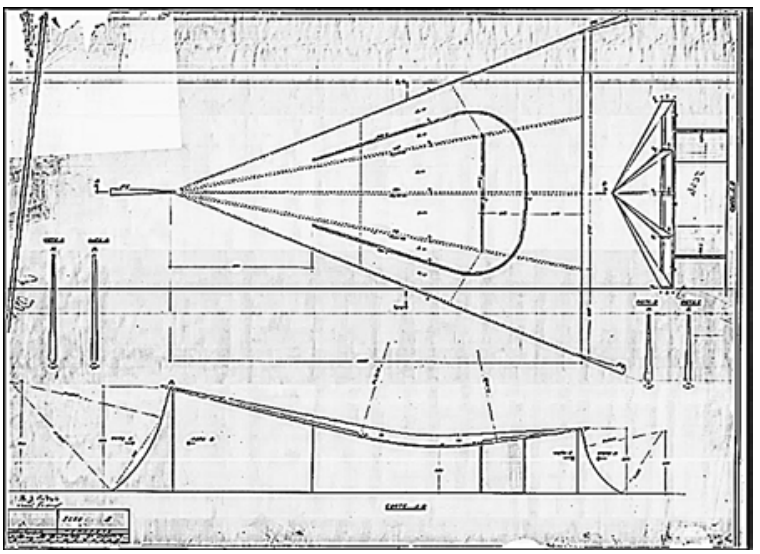

Fonte: DAU/NOVACAP. Arquivo Público do Distrito Federal

Figura 8: Projeto das estruturas de fundações.

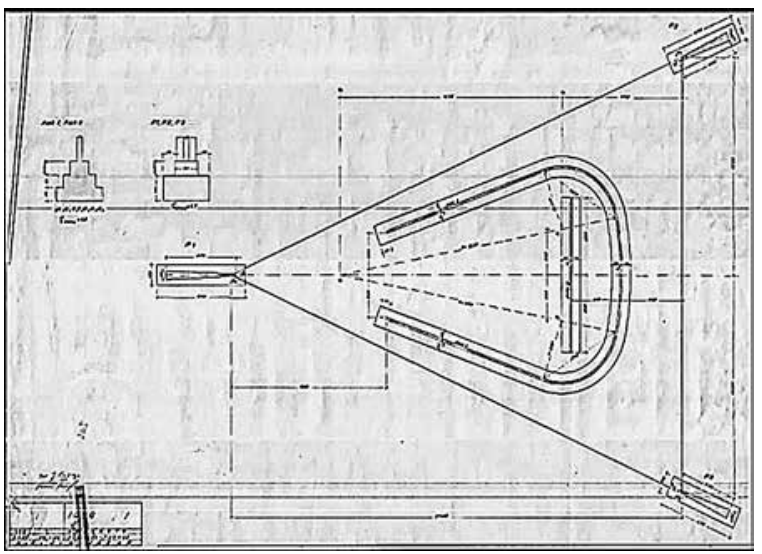

Fonte: DAU/NOVACAP. Arquivo Público do Distrito Federal

Figura 9: Projeto de forma da estrutura do pavimento térreo.

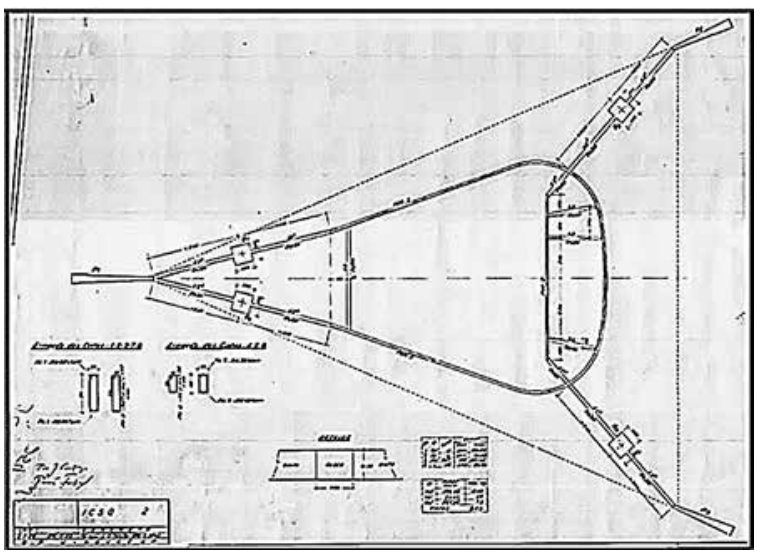

Fonte: DAU/NOVACAP. Arquivo Público do Distrito Federal

\section{Forma e Função Estrutural}

As intenções plásticas de Niemeyer estão representadas nas fachadas da Igrejinha, na busca da força expressiva da leveza e do desafio da técnica. Para seguir essa intenção arquitetônica, o engenheiro Joaquim Cardozo utilizou um arranjo estrutural que não indica com clareza o caminho percorrido pelas forças. A primeira impressão é de 
que a laje de cobertura se apoia exclusivamente nas vigas que compõem as fachadas laterais do prédio e que por sua vez simplesmente apoiam-se nos pilares de seção variáveis P1, P2 e P3.

Segundo Rebello (2000), um pré-dimensionamento adequado para a altura de vigas de concreto armado de alma cheia com vão de 12,0 m encontra-se em um intervalo de $L / 13$ a $L / 15$, sendo " $L$ " o comprimento do vão livre. Aplicando essa relação geométrica para a viga da fachada lateral da Igrejinha, com um vão aparente de $31,5 \mathrm{~m}$, o resultado seria uma altura de aproximadamente 220 $\mathrm{cm}$. O projeto desenvolvido por Cardozo determinou, no trecho central onde apresenta maior inércia da viga, uma altura de apenas $90 \mathrm{~cm}$ para a viga.

Porém, após análise mais criteriosa dos desenhos de forma e armação da estrutura da cobertura do prédio, constata-se que há faixas de reforço armadas longitudinalmente com larguras variáveis e com a mesma espessura da laje, apoiadas nas paredes estruturais de concreto armado que oferecem um suporte intermediário para as vigas de contorno das fachadas da Igrejinha (Figura 10).

Figura 10: Projeto de armação da estrutura da cobertura com as faixas de reforço.

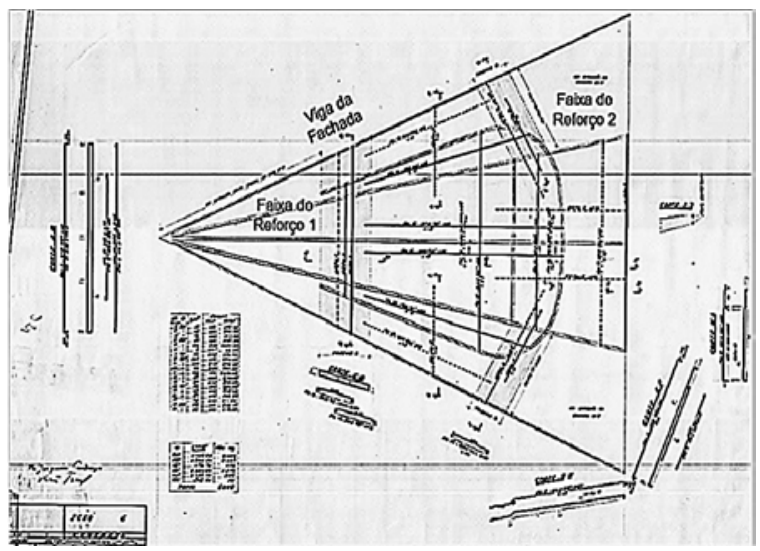

Fonte: DAU/NOVACAP. Arquivo Público do Distrito Federal

De acordo com Nervi (1959), após sua visita a Brasília em 1959, se de fato a cobertura da Igrejinha estivesse apoiada apenas nos pilares em "V", a ancoragem do lençol de concreto nos pilares geraria tensões horizontais e, consequentemente, momentos de engaste na base dos pilares tão elevados que seria permitido duvidar da possibilidade de execução deste projeto.

Contudo, considerando esses apoios intermediários, as vigas das fachadas transformam-se em elementos contínuos de três vãos e quatro apoios, distribuindo melhor os esforços e reduzindo os momentos fletores atuantes, o que faz com que parte do carregamento seja transferido também para as paredes estruturais de concreto armado localizadas no interior do prédio.
Esses suportes intermediários comportam-se como apoios elásticos ou molas, absorvendo a reação de apoio às custas de sua deformação na direção dessa força. O deslocamento de um apoio elástico é proporcional à força aplicada $\mathrm{F}$ e depende da rigidez de sua geometria, representada pelo coeficiente $\mathrm{K}$.

Para conhecermos o valor de K em uma determinada seção de apoio, definida como a constante de mola, aplica-se uma força $F$ para verificação do respectivo deslocamento vertical. Um número pequeno para K, próximo de zero, significa a ausência de apoio, assim como um valor muito grande, que possa representar o infinito, descreve as condições de um suporte rígido (Sussekind, 1976).

Assim, considerando a aplicação de uma força unitária na seção de apoio da estrutura, o coeficiente de rigidez da mola $(\mathrm{K})$ será dado pelo inverso do deslocamento nesse ponto (Equação 1):

$$
F=1,0(t f) \therefore K=\frac{1,0}{\mathrm{D}}\left(\frac{t f}{\mathrm{~cm}}\right)
$$

Aplicando uma força unitária nos pontos em que as faixas de reforços da laje de cobertura apoiam a viga da fachada e utilizando um módulo de elasticidade de $250 \mathrm{tf} / \mathrm{cm}^{2}$ para o concreto, obteve-se os valores de $17 \mathrm{tf} / \mathrm{cm}$ para a constante de mola (K) da faixa 1 e $9 \mathrm{tf} / \mathrm{cm}$ para a faixa 2 . A maior rigidez da faixa de reforço 1 demonstra a sua condição menos deformável, determinada pela utilização de dois pontos fixos de apoio, devidamente afastados e localizados nas paredes estruturais do interior do prédio. A faixa de reforço 2 está apenas engastada e livre (Figura 10).

O software Ftool utilizado permite a análise qualitativa de estruturas planas, a partir da construção de modelos teóricos simplificados, representados pelos eixos dos elementos estruturais e submetidos a carregamentos unitários. Assim, foram desenvolvidos dois modelos para análise do comportamento estrutural da viga da fachada da Igrejinha.

Com o objetivo de representar a variação de inércia proposta no projeto de arquitetura, o modelo teórico considerou a viga da fachada dividida em três trechos longitudinais, I, II e III, sendo a altura da seção transversal definida a partir do ponto médio de cada um desses segmentos. Da mesma forma, a linha de eixo dos pilares foi dividida em trechos de 1,0 m e a altura da seção transversal foi obtida a partir do ponto médio de cada segmento (Figura 11). 
Figura 11: Viga da fachada: variação das seções.

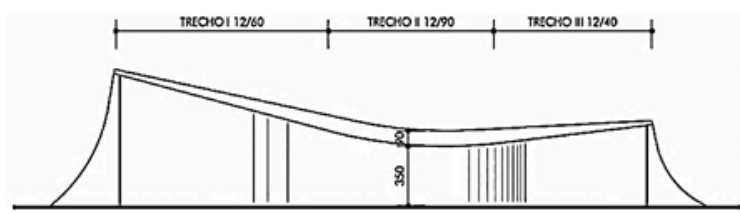

Fonte: Arakaki, 2012

As bases dos pilares, por terem inércias elevadas, foram engastadas na fundação, utilizando um vínculo que restringisse todos os movimentos. A ligação da viga com os pilares, porém, devido à relação de suas geometrias, foi considerada rotulada, permitindo no modelo teórico a livre rotação entre os elementos.

O primeiro modelo (1) representa a viga da fachada sem a consideração dos apoios elásticos, ou seja, com os valores nulos das constantes de mola, fazendo com que o elemento estrutural fique biapoiado nos pilares triangulares do prédio (Figura 12).

Figura 12: Modelo 1 - carregamento.

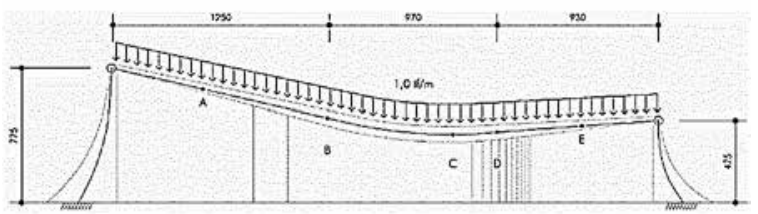

Fonte: Arakaki, 2012

O modelo 2 utiliza os apoios elásticos fornecidos pelas faixas de reforço 1 e 2 , com os seus respectivos valores de rigidez de $17 \mathrm{tf} / \mathrm{cm}$ e $9 \mathrm{tf} / \mathrm{cm}$ (Figura 13). Os dois modelos foram analisados, de maneira qualitativa, por uma carga unitária uniformemente distribuída com o valor de 1,0 tf/m (Figura 14).

Figura 13: Modelo 2 - carregamento.

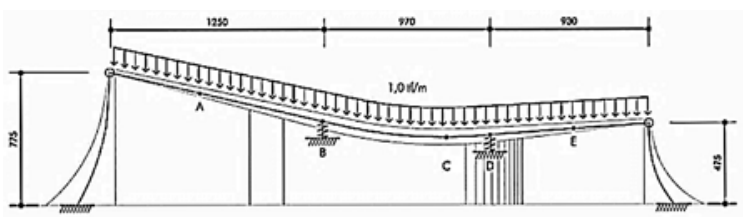

Fonte: Arakaki, 2012

Figura 14: Viga da fachada - diagramas de deslocamentos para diferentes situações de rigidez dos apoios elásticos das faixas de reforço.

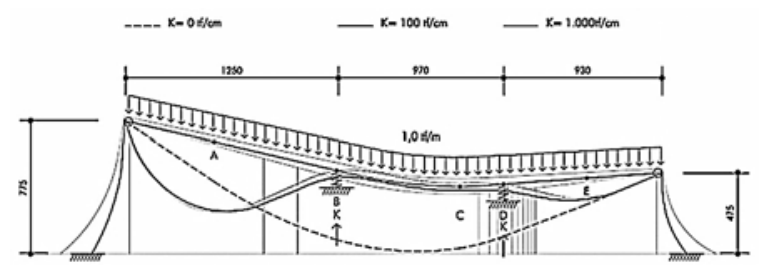

Fonte: Arakaki, 2012
O diagrama de deslocamentos verticais mostrou no primeiro modelo um valor máximo de $588 \mathrm{~mm}$, enquanto que no segundo modelo, esse valor foi reduzido para $38 \mathrm{~mm}$ (Figura 15 e Figura 17).

Como referência para a nossa análise, a Norma Brasileira ABNT:NBR 6118:2014 apresenta o valor de L/250 como o limite para aceitabilidade sensorial dos deslocamentos estruturais visíveis, sendo L o vão maior da viga, no que resulta nos valores máximos de $126 \mathrm{~mm}$ no primeiro modelo e de 42 $\mathrm{mm}$ no segundo.

Figura 15: Modelo 1 - diagrama de deslocamentos.

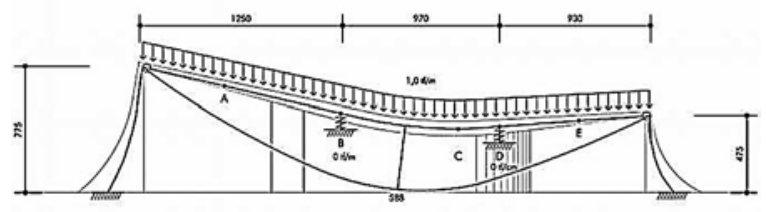

Fonte: Arakaki, 2012

Figura 16: Modelo 1 - diagrama de momento fletor.

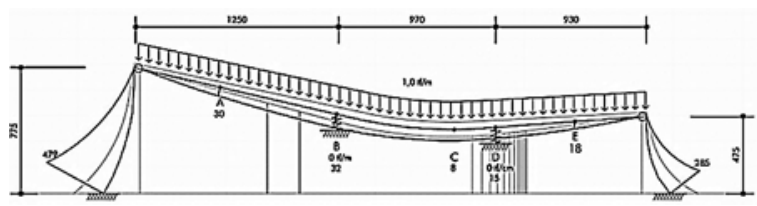

Fonte: Arakaki, 2012

Os momentos fletores nas bases dos pilares de apoio também revelaram as diferenças dos comportamentos estruturais dos dois modelos. No primeiro, a viga da fachada, biapoiada nos pilares triangulares com um vão de $31,5 \mathrm{~m}$, transfere para eles o total do carregamento recebido e um momento máximo de $479 \mathrm{tfm}$. O segundo modelo, com a utilização dos apoios elásticos, transmite um momento fletor máximo de $13 \mathrm{tfm}$ para o pilar de apoio, indicando uma distribuição das cargas atuantes para as paredes estruturais localizadas no interior do prédio (Figura 16 e Figura 18).

Figura 17: Modelo 2: diagrama de deslocamentos

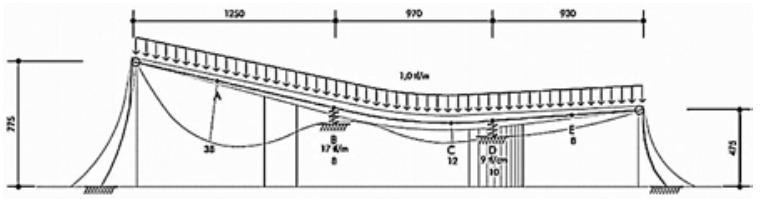

Fonte: Arakaki, 2012

Figura 18: Modelo 2: diagrama de momento fletor

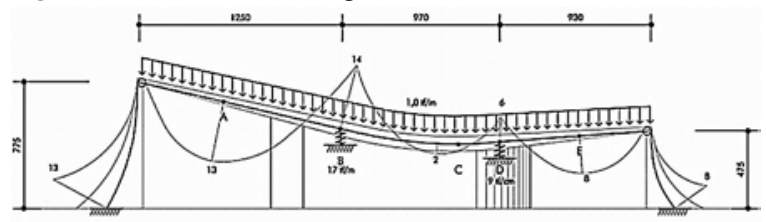

Fonte: Arakaki, 2012 


\section{Conclusão}

O projeto da Igreja Nossa Senhora de Fátima é marcado pela síntese projetiva entre a forma arquitetônica e a função estrutural, característica das obras do arquiteto Oscar Niemeyer desenvolvidas em parceria com o engenheiro Joaquim Cardozo. $\mathrm{O}$ dimensionamento procura dar leveza à estrutura com a intenção de fazer a cobertura parecer um elemento desprovido de peso, fixada em três pontos de apoio.

Todas as decisões de projeto foram dirigidas para cumprir esse objetivo. $O$ desenho curvo no plano da cobertura, afinando em direção às extremidades, o recuo do invólucro da igreja e o desenho das formas, sugerem a leveza do edifício. Confirmando que o repertório formal de Niemeyer é transformado e aprimorado em cada novo projeto, percebe-se que essa intenção arquitetônica já tinha sido ensaiada na construção da Casa Edmundo Cavanelas.

Nesse projeto, a cobertura apresenta-se como uma catenária, formada por materiais leves, apoiada em um conjunto de treliças metálicas suportadas por quatro colunas e dois muros de alvenaria de pedra. A Igrejinha, contudo, possui todos os elementos em concreto armado, uma cobertura composta por laje maciça e apenas três pilares de apoio, aumentando as solicitações na estrutura.

Joaquim Cardozo viabilizou a construção da Igrejinha consciente da importância de sua impressão plástica em detrimento da leitura imediata da solução estrutural. Para seguir a intenção arquitetônica proposta por Niemeyer, Cardozo utilizou um arranjo estrutural que não indica com clareza o caminho percorrido pelas forças, o oposto da forma pura encontrada na Catedral Metropolitana.

A fachada lateral é a principal responsável pela transmissão do conceito de leveza e audácia estrutural da Igrejinha, fazendo inclusive que o engenheiro italiano Pier Luigi Nervi hesitasse sobre o seu comportamento. Os desenhos de forma e armação da cobertura da Igrejinha e uma análise qualitativa da viga da fachada, contudo, revelam o arranjo estrutural de Cardozo, que utilizou suportes elásticos com o auxílio de faixas de reforço apoiadas nas paredes estruturais internas do prédio.

A ausência de pureza estrutural no projeto da Igrejinha, iludindo o observador quanto ao seu comportamento estrutural, pode contrariar aspectos relacionados aos custos de construção, porém, concede um espaço importante para o atendimento de exigências plásticas do projeto.

Independentemente da clareza na leitura da solução estrutural, o projeto da Igrejinha, mesmo para os dias atuais, mais de 50 anos após sua construção, apresenta audácia na sua concepção, demonstrando a capacidade inventiva de Oscar Niemeyer e Joaquim Cardozo diante das limitações construtivas e do reduzido cronograma que caracterizavam as obras de Brasília, definindo a linguagem arquitetônica daquele momento.

\section{Referências}

ABNT - ASSOCIAÇÃO BRASILEIRA DE NORMAS TÉCNICAS. NBR 6118 - Projeto de Estruturas de Concreto - Procedimento. 2014.

ARAKAKI, Suyene Riether. Igreja Católica de Superquadra: origens da concepção arquitetônica, 2012. 185p.:il. Dissertação (Mestrado em Arquitetura e Urbanismo) - Faculdade de Arquitetura da Universidade de Brasília, Brasília. 2012.

MARTHA, Luiz Fernando. Ftool: Two Dimensional Frame Analysis Tool - Versão Educacional 3.0 Rio de Janeiro: Tecgraf/PUC/Rio, 2008.

NERVI, Pier Luigi. Critica delle strutture. Architettura e strutturalismo. Casabella-Continuità, n²29, Itália, jan. 1959.

NIEMEYER, Oscar. Conversa de amigos: corremspondência entre Oscar Niemeyer e José Carlos Sussekind. Rio de Janeiro: Revan, 2002. 256p.

REBELLO, Yopanan Conrado Pereira. A Concepção Estrutural e a Arquitetura. São Paulo: Zigurate, 2000.

ROSENTHAL, Hans Werner. Structural decisions. London: Chapman \& Hall/CRC, 1962. 417p.

SANTA CECÍLIA, Bruno. Tectônica moderna e construção nacional. Revista mdc, Disponível em: http://revistamdc.files.wordpress.com/2008/12/ mdc01-txt02.pdf. Acesso em: 13/outubro/ 2009.

SIEGEL, Curt. Formas estructurales en la arquitectura moderna. Traduzido por Francisco Luis Maigler, México: Compañia Editorial Continental, 1966, 311p.

SÜSSEKIND. José Carlos. Curso de análise estrutural. Vol. II. Porto Alegre: Globo, 1976. v. ilust. 309p.

TAMANINI, Lourenço Fernando. Brasília: memória da construção. v.1. Brasília: Projecto Editorial, 2003.

TEATINI CLÍMACO, J.C.; PESSOA, D. F. Catedral de Brasília: histórico de projeto/ execução e análise da estrutura. Revista Internacional de Desastres Naturales, Accidentes e Infraestructura Civil, Porto Rico, v. 2, n.2, p. 79-88, 2002.

WEINTRAUB, Alan; HESS, Alan. Oscar Niemeyer, Casas. Barcelona: Editorial Gustavo Gili, 2011. 
